\title{
Hepatitis B infection awareness, vaccine perceptions and uptake, and serological profile of a group of health care workers in Yaoundé, Cameroon
}

Henri Olivier Pambou Tatsilong ${ }^{1,2}$, Jean Jacques N. Noubiap ${ }^{3,4^{*}}$, Jobert Richie N. Nansseu ${ }^{5}$, Leopold N. Aminde ${ }^{6,7}$, Jean Joel R. Bigna ${ }^{8}$, Valentine Ngum Ndze ${ }^{9}$ and Roger Somo Moyou ${ }^{10}$

\begin{abstract}
Background: Cameroon is one of the countries in Africa with the highest burden of Hepatitis B infection. Health care workers are known to be at risk of occupational exposure to blood and other infectious bodily fluids. The aim of this study was to assess the profile of serological markers of hepatitis B virus (HBV) infection, knowledge and perceptions regarding HBV infection among health care workers in a health area in Yaoundé.

Methods: A cross-sectional study was conducted in the Mvog-Ada Health Area of the Djoungolo Health District from March 1 to November 31, 2014. All consenting health care workers were included in the study. Serological markers of HBV (HBs Ag, Hbe Ag, anti-HBs Ab, anti-HBe Ab, anti-HBc Ab) were qualitatively tested using Biotech $^{\oplus}$ (OneHBV-5 parameter rapid test website) in each participant and the anti-HBs antibodies were quantified by ELISA (Biorex) among those who were positive with the qualitative test. Chi square test or its equivalents were used to compare qualitative variables and a $p$-value less than or equal to 0.05 was considered significant.

Result: A total of 100 participants were retained for the study out of 163 in the health area giving a response rate of $61.34 \%$; the mean age was 30.5 (SD 6.8) years and $71 \%$ of participants were women. Forty seven percent (47 \%) of workers had good level of knowledge of HBV infection. The men were 3.20 times (95 \% Cl: 1.02-9.19, $p=0.04$ ) more likely to have a good level of knowledge than women. Participants with a university study level were more (95\% Cl: 3. $17-25, p<0.0001$ ) likely to have a good level of knowledge than those with a high school study level. Ninety-six percent of participants thought that they were at a greater risk of becoming infected with HBV than the general population, $93 \%$ felt that the vaccine should be compulsory and all (100 \%) were willing to recommend it to others. However, only $19 \%$ had received at least one dose of the vaccine. The proportion of HBs Ag was $11 \%$. The different serological profiles with regard to HBV infection were naive subjects (62\%), chronic carriers (11\%), vaccinated (19\%) and subjects naturally immunized ( $8 \%$ ). Three out of the 19 participants who received at least one dose of the vaccine, only 9 (47.4 \%) of whom had titers $\geq 100 \mathrm{IU} / \mathrm{I}$ indicating a good response to vaccination. Among those who received three doses of the vaccine $(n=12,63 \%), 2(16,66 \%)$ had poor response to vaccination (HBs Ab titers $<100$ IU/I).

Conclusion: The prevalence of HBs Ag among health care workers in the Mvog-Ada Health Area is high (11\%). These workers are at high risk of HBV infection because of very low vaccine uptake and poor post-exposure practices. Their knowledge of HBV infection is non-optimal.
\end{abstract}

Keywords: Viral hepatitis B, Health care workers, Knowledge, Vaccine, Serological markers

\footnotetext{
* Correspondence: noubiapjj@yahoo.fr

${ }^{3}$ Department of Medicine, Groote Schuur Hospital and University of Cape

Town, 7295 Cape Town, South Africa

${ }^{4}$ Medical Diagnostic Center, Yaoundé, Cameroon

Full list of author information is available at the end of the article
} 


\section{Background}

Hepatitis B virus (HBV) infection is a major health problem worldwide owing to its high prevalence and significant morbidity and mortality. According to a recent systematic review and meta-analysis estimating the worldwide prevalence of chronic HBV infection, in 2010, about 248 million individuals were hepatitis B surface antigen (HBs Ag) positive [1]. More than 780000 people die every year due to hepatitis B-related complications including cirrhosis and hepatocellular carcinoma [2]. The prevalence of HBV chronic infection is particularly high in Africa, prevalence reaching up to $22 \%$ in South Sudan [1]. In Cameroon, seroprevalence of HBs Ag has been reported to be $10.1 \%$ in a general population of blood donors [3], $10.2 \%$ among pregnant women [4] and $23.7 \%$ among HIV-infected patients [5].

Health care workers are at a high risk of HBV infection through occupational exposure to blood, and the incidence of this infection among them has been estimated to be 2-4 times the level in the general population [6]. As part of occupational safety measures, it has been recommended that all health care workers should be vaccinated against HBV [7]. In fact, HBV infection is preventable for more than twenty years through effective prophylactic vaccination [8]. But intriguingly, WHO has reported that $\mathrm{HBV}$ vaccination coverage amongst health care workers is only 18-39\% in low-and middle-income countries (LMIC) compared to $67-79 \%$ in high-income countries [9].

In Cameroon, few studies have been done on the epidemiology of HBV among health care providers. We previously conducted two studies among surgical residents [10] and medical students [11] in Cameroon which showed that despite a good knowledge of the risk factors for $\mathrm{HBV}$ infection and awareness of $\mathrm{HBV}$ vaccine, only $24.5 \%$ and $18 \%$ of these respective populations were adequately vaccinated against HBV. The main limitation of these studies was the absence of serological testing to determine the prevalence of $\mathrm{HBV}$ infection and the immune status of participants. We therefore conducted the current study which aimed to evaluate knowledge of HBV infection, HBV vaccine uptake, and serological profile of a group of health care workers in Yaoundé, Cameroon.

\section{Methods}

\section{Study design, Setting and population}

This was a cross-sectional study conducted from March to November 2014 in the Mvog-Ada Health Area, which is part of the Djoungolo Health District, one of the eight health districts of Yaoundé, the capital city of Cameroon. This health area covers an average population of 82,000 inhabitants and comprises six health facilities with a total of 163 health care workers during the study period.
Participants were health care providers working in one of the health centers of Mvog-Ada Health Area, irrespective of their age, sex, background or seniority, who were at their post when the investigator visited, and who voluntarily accepted to take part in the study. The sample size was calculated, considering a $6.6 \%$ prevalence of HBs Ag carriage among health care workers as reported by Noah et al. [12] in Yaoundé, and a $5 \%$ level of precision; hence a minimum of 96 subjects was required.

\section{Data collection and laboratory investigation}

A structured pretested questionnaire was used to collect socio-demographic information (age, sex, qualification and year experience) and data on risk factors for HBV infection among participants (practice and attitude). Upon completion of the questionnaire, $5 \mathrm{ml}$ of venous blood was aseptically collected by venipuncture into an Ethylene Di-amine Tetra-acetic Acid (EDTA) tube. The plasma obtained from each sample was tested for serological markers of $\mathrm{HBV}$ including $\mathrm{HBs} \mathrm{Ag}$, hepatitis $\mathrm{B}$ e antigen (Hbe Ag), hepatitis B surface antibodies (anti-HBs Ab), hepatitis $\mathrm{B}$ e antibodies (anti-HBe $\mathrm{Ab}$ ), and hepatitis $\mathrm{B}$ core antibodies (anti-HBc Ab). These tests were performed using a qualitative test Biotech ${ }^{\oplus}$ (OneHBV-5 parameter rapid test website, CTK Biotech, Inc. 6748 Nancy Ridge Drive, San Diego, CA 92121, USA) in each participant, and the anti-HBs Ab were further quantified by ELISA (Biorex Diagnostics Limited, Unit 2C Antrim Technology Park, Muckamore; United Kingdom) among those who were positive with the qualitative test.

\section{Assessment of knowledge on $\mathrm{HBV}$ and $\mathrm{HBV}$ vaccination}

The level of knowledge of participants on HBV and HBV vaccination was estimated using a score based on their responses to 13 questions. Each corrected answer was allocated 1 point, giving a total score of 13 points. A good level of knowledge was considered as at least 10/13. This minimum of 10/13 defining a good level of knowledge may seem rigorous. However, this minimum level justified an affordable difficulty of the questions.

\section{Serological profile and immune status}

The following definitions were applied [13]:

\begin{tabular}{llllll}
\hline & $\mathrm{HBs} A g$ & $\mathrm{HBe} A g$ & $\mathrm{HBs} A b$ & $\mathrm{HBe} A b$ & $\mathrm{HBc} A b$ \\
\hline Naive subjects & - & - & - & - & - \\
Chronic carriers & + & - & - & + & + \\
Subjects vaccinated & - & - & + & - & - \\
Subjects naturally & - & - & + & - & + \\
immunized & & & & & \\
Acute hepatitis & + & + & - & + & - \\
\hline
\end{tabular}

+: positive - : negative 
Regarding immune status, participants with a HBs Ab titer under $10 \mathrm{IU} / \mathrm{L}$ were considered unimmunized, those with a titer between $10 \mathrm{IU} / \mathrm{L}$ and $100 \mathrm{IU} / \mathrm{L}$ were considered being poorly immunized and those with a titer equal or greater than $100 \mathrm{IU} / \mathrm{L}$ had good immunity against HBV [14].

\section{Data analysis}

Data were coded, entered and analyzed using IBM SPSS software (Version 20, Chicago, Illinois, USA). Results are presented as counts (proportions) for categorical variables, and means with standard deviations (SD) for quantitative ones. Odds ratios (OR) with their $95 \%$ confidence intervals $(\mathrm{CI})$ served to investigate the influence of various factors on the occurrence of $\mathrm{HBV}$ infection, and were calculated by both univariate and multivariate logistic regression analyses while adjusting for potential confounders. We included in the multivariate model the age and all variables with a $p$ value $\leq 0.2$ in univariate analyses. For this purpose, we categorized some variables into two groups. The age was grouped into two classes: $\leq 30$ and $>30$ years. Educational level was classified as 'low' for participant having a secondary level of education or less, and 'high' for those with a University level of education or more. Specialty was categorized as Laboratory for "Laboratory technician, Assistant laboratory technician" and Medicine for "Doctor, Nurse and Midwife". The professional experience was dichotomized in two groups: $\leq 6$ years and $>6$ years. The cut-off of 6 years was chosen because it represents the median duration of work experience among our participants. A $p$ value $<0.05$ was set to characterize statistically significant results.

\section{Results}

\section{General characteristics}

Of the 163 health care workers in the health area, 100 were included in the study giving a participation rate of $61.34 \%$. The mean age was 30.5 (SD 6.8) years and the male/female sex ratio was 0.40 . We enrolled three doctors (3\%), seven midwifes (7\%), 13 laboratory technicians (13\%), 21 nurses (21\%), 28 nurse aids (28\%), 11 assistant laboratory technicians (11\%) and 17 auxiliary staffs (17\%) (Table 1).

\section{Level of knowledge on HBV and correlates}

Forty seven participants $(47 \%)$ had a right level of knowledge of HBV infection. Only $26 \%$ of participants were aware that $\mathrm{HBV}$ is the most contagious blood-borne virus. Most of participants correctly identified injury with contaminated needle (96\%), sexual intercourses (96\%), mother-to-child transmission (96\%) and blood transfusion (99\%) as routes of contamination with $\mathrm{HBV}$. All of them were aware of the
Table 1 Distribution of participants according to age, sex, level of education and number of years of service

\begin{tabular}{|c|c|}
\hline Characteristics & Number or percentage $^{a}$ \\
\hline \multicolumn{2}{|l|}{ Age } \\
\hline $20-29$ & 43 \\
\hline $30-39$ & 44 \\
\hline $40-55$ & 14 \\
\hline \multicolumn{2}{|l|}{ Sex } \\
\hline Male & 29 \\
\hline Female & 71 \\
\hline \multicolumn{2}{|l|}{ Level of education } \\
\hline Secondary & 53 \\
\hline University & 47 \\
\hline \multicolumn{2}{|l|}{ Qualification } \\
\hline Nurse aids & 28 \\
\hline Lab technician & 13 \\
\hline Assistant lab technician & 11 \\
\hline Nurse & 21 \\
\hline Midwife & 7 \\
\hline Doctor & 3 \\
\hline Auxiliary staff & 17 \\
\hline \multicolumn{2}{|l|}{ Service } \\
\hline Laboratory & 28 \\
\hline Maternity & 19 \\
\hline Surgery & 7 \\
\hline Medicine & 46 \\
\hline \multicolumn{2}{|l|}{ Professional experience } \\
\hline$<6$ & 60 \\
\hline$\geq 6$ & 40 \\
\hline
\end{tabular}

aTotal enrollment is 100 , the number of the group are identical to the percentages

existence of a vaccine to prevent $\mathrm{HBV}$ infection, up to $77 \%$ knew that the minimum number of doses for a complete primary $\mathrm{HBV}$ vaccination is 3 doses, but only $57 \%$ knew that an immune response test should be done after $\mathrm{HBV}$ vaccination to confirm a good immunization status (Table 2). As shown in Table 3 , in multivariate analysis, men were 3.20 times more likely to have a good level of knowledge than women (95\% CI: $1.02-9.19, p=0.04)$. Participants with a high educational level were 8.85 times more likely to have a good level of knowledge than those with at most a high school study level (95 \% CI: 3.17-25, $p<0.0001$ ).

Perception of HBV vaccine, vaccination status and history of exposure to blood

Ninety-six percent of participants thought that they were at a greater risk of becoming infected with $\mathrm{HBV}$ than 
Table 2 Knowledge of risk factors and HBV vaccination among 100 health workers in Cameroon

\begin{tabular}{ll}
\hline Statements & $\begin{array}{l}\text { Correct answers } \\
\text { Frequency or percentage }\end{array}$ \\
\hline $\begin{array}{l}\text { 1. HBV is the most contagious blood-borne } \\
\text { pathogen through accidental exposure to } \\
\text { blood }\end{array}$ & 26 \\
2. Contact of healthy skin with infected & 46 \\
blood is a risk factor of HBV infection & \\
3. Injury with needle contaminated with & 96 \\
infected blood is a risk factor of HBV & \\
infection & \\
4. Contact of abraded skin with infected \\
body fluid is a risk factor of HBV infection
\end{tabular}

$H B V$ hepatitis $B$ virus the general population and $93 \%$ felt that vaccination against HBV should be compulsory for all health care workers and all of them (100\%) were willing to recommend it to others colleagues. While $67 \%$ of participants considered the HBV vaccine as safe, only $19 \%$ had received at least one dose of the vaccine. Among those who never had any dose of the HBV vaccine $(n=81)$, the reasons for not being vaccinated were lack of sufficient information on the vaccine $(49.4 \%, n=40)$, lack of money to pay for the vaccine $(33.3 \%, n=27)$, lack of time $(12.3 \%, n=10)$ and lack of motivation $(4.9 \%$, $n=4)$. Moreover, $41 \%$ of participants had been informed by their training institution or by the administration of their health facility about the importance of being vaccinated against HBV. All unvaccinated participants were willing to receive the HBV vaccine.

Regarding history of accidental exposure, while $64 \%$ of participants reported occupational exposure to HBV in the past, only $35.9 \%(n=23)$ of them had always notified the exposure and $75 \%(n=48)$ never considered the risk of HBV infection after exposure but only the risk of HIV infection.

\section{Serological profile}

The frequency of $\mathrm{HBs} \mathrm{Ag}$ was $11 \%$, while that of $\mathrm{HBs} \mathrm{Ab}$ was $26 \%$ (Table 4). Sixty-two percent of subjects were naive to HBV and mostly females $(74.2 \%, n=46)$. Those working outside the laboratory $(79 \%, n=49)$ and those with less than 6 years of professional experience $(64.5 \%$, $n=40$ ). Nineteen percent were vaccinated, mostly those working outside the laboratory $(73.7 \%, n=14)$, females

Table 3 Unadjusted and adjusted factors associated with good knowledge of HBV infection

\begin{tabular}{|c|c|c|c|c|c|c|}
\hline Variable & Total & Good knowledge n (\%) & OR $(95 \% \mathrm{Cl})$ & $p$ value & $\mathrm{aOR}(95 \% \mathrm{Cl})$ & $p$ value \\
\hline \multicolumn{7}{|l|}{ Age } \\
\hline$\leq 30$ & 50 & $22(44)$ & $0.46(0.15-1.54)$ & 0.21 & $0.43(0.16-1.2)$ & 0.10 \\
\hline$>30$ & 50 & $25(50)$ & 1 & & 1 & \\
\hline \multicolumn{7}{|l|}{ Sex } \\
\hline Male & 29 & $22(75.86)$ & $3.44(1.075-1.032)$ & 0.03 & $3.19(1.02-9.91)$ & 0.04 \\
\hline Female & 71 & $25(35.21)$ & 1 & & 1 & \\
\hline \multicolumn{7}{|c|}{ Level of education } \\
\hline University & 47 & $35(74.46)$ & $8.20(2.87-23.81)$ & $<0.0001$ & $8.85(3.17-25)$ & $<0.0001$ \\
\hline Secondary & 53 & $12(22.64)$ & 1 & & 1 & \\
\hline \multicolumn{7}{|l|}{ Service } \\
\hline Laboratory & 28 & $15(53.57)$ & $3.70(0.32-42.67)$ & 0.29 & & \\
\hline Medicine & 72 & $32(44.44)$ & 1 & & & \\
\hline \multicolumn{7}{|c|}{ Professional experience } \\
\hline$<6$ years & 60 & $30(50)$ & $0.85(025-285)$ & 0.79 & & \\
\hline$\geq 6$ years & 40 & $17(42.50)$ & 1 & & & \\
\hline
\end{tabular}

$O R$ odds ratio, $a O R$ adjusted odds ratio, $\mathrm{Cl}$ confidence interval

The variables introduced in the multivariable model were age, sex and educational level 
Table 4 Distribution of following serological markers according to the qualification

\begin{tabular}{|c|c|c|c|c|c|c|}
\hline Qualification & HBs Ag positive & HBs Ab positive & HBe Ag positive & HBe Ab positive & $\mathrm{HBC}$ Ab positive & Total \\
\hline Nurse aid & $3(10.7)$ & $6(21.4)$ & $0(0)$ & $3(10.7)$ & $5(17.9)$ & 28 \\
\hline Assistant Lab technician & $2(18.1)$ & $2(18.1)$ & $0(0)$ & $2(18.1)$ & $2(18.1)$ & 11 \\
\hline Lan technician & $4(30.8)$ & $5(38.5)$ & $0(0)$ & $5(38.5)$ & $8(61.5)$ & 13 \\
\hline Nurse & $2(9.5)$ & $6(28.6)$ & $1(4.8)$ & $1(4.8)$ & $3(14.3)$ & 21 \\
\hline Doctor & $0(0)$ & $1(33.3)$ & $0(0)$ & $0(0)$ & $0(0)$ & 3 \\
\hline Midwife & $0(0)$ & $2(28.6)$ & $0(0)$ & $0(0)$ & $0(0)$ & 7 \\
\hline Auxiliary staff & $0(0)$ & $4(23.5)$ & $0(0)$ & $1(5.9)$ & $0(0)$ & 17 \\
\hline Total & $11(11)$ & $26(26)$ & $1(100)$ & $12(12)$ & $18(18)$ & 100 \\
\hline
\end{tabular}

$(63.2 \%, n=12)$ and those with less than 6 years of professional experience $(63.2 \%, n=12)$. Eight percent were naturally immunized and $11 \%$ chronic carriers (Table 5).

Serologically immunized participants (19\%) where all those who reported having received at least one dose of HBV vaccine. Among unvaccinated participants; $8.6 \%$ had the anti-Hbs ab, anti-HBc $\mathrm{Ab}$ and anti- Hbe Ab; these markers reflect a natural immunity. We quantified $\mathrm{HBs} \mathrm{Ab}$ and titers ranged from $0 \mathrm{IU} / 1$ to $251 \mathrm{IU} / \mathrm{l}$. Three out of the 19 participants who were vaccinated (15.8\%) had HBs Ab titers <10 IU/l, while 7 (36.8 \%) had titers $\geq 10 \mathrm{IU} / \mathrm{l}$ and $<100 \mathrm{IU} / \mathrm{l}$, and 9 (47.4 \%) had titers $\geq 100 \mathrm{IU} / \mathrm{l}$ indicating a good response to vaccination. Among those who received three doses of the vaccine $(n=9), 2$ had poor response to vaccination (HBs Ab titers < $100 \mathrm{IU} / \mathrm{l})$.

Table 5 Hepatitis B serological profiles according to age, sex, level of education, service and experience

\begin{tabular}{|c|c|c|c|c|c|}
\hline Characteristics & Naive & Vaccinated & $\begin{array}{l}\text { Naturally } \\
\text { immunized }\end{array}$ & $\begin{array}{l}\text { Chronic } \\
\text { carrier }\end{array}$ & Total \\
\hline \multicolumn{6}{|l|}{ Age } \\
\hline$\leq 30$ & 33 & 8 & 1 & 8 & 50 \\
\hline$>30$ & 29 & 11 & 7 & 3 & 50 \\
\hline \multicolumn{6}{|l|}{ Sex } \\
\hline Male & 16 & 7 & 1 & 5 & 29 \\
\hline Female & 46 & 12 & 7 & 6 & 71 \\
\hline \multicolumn{6}{|c|}{ Educational level } \\
\hline University & 28 & 9 & 4 & 6 & 47 \\
\hline Secondary & 34 & 10 & 4 & 5 & 53 \\
\hline \multicolumn{6}{|l|}{ Service } \\
\hline Laboratory & 13 & 5 & 4 & 6 & 28 \\
\hline Medicine & 49 & 14 & 4 & 5 & 72 \\
\hline \multicolumn{6}{|l|}{ Experience } \\
\hline$<6$ years & 40 & 12 & 1 & 7 & 60 \\
\hline$\geq 6$ years & 22 & 7 & 7 & 4 & 40 \\
\hline Total & 62 & 19 & 8 & 11 & 100 \\
\hline
\end{tabular}

\section{Discussion}

The current study was designed to assess knowledge of $\mathrm{HBV}$ infection, HBV vaccine perception and uptake, and determine the serological profile of a group of health care workers in Yaoundé, Cameroon. Forty-seven percent of the participants had a good level of knowledge on HBV infection. After adjusting for confounders, correlates of a good level of knowledge included male gender and high educational level. The uptake of HBV vaccine was very low (19\%). Serological testing showed that $62 \%$ of participants were naïve to HBV, $10 \%$ were chronic carriers. Among the 19 participants who received at least one dose of the vaccine, only 9 had a good response to vaccination.

In two previous studies, we reported good knowledge about HBV infection among medical students [11] and surgical residents [10], contrasting with the findings of the current study which revealed that only $47 \%$ of health care workers had a good level of knowledge. This difference is most likely due to the fact that participants with high educational level were about 9 times more prone to have a right level of knowledge as had surgical residents or medical students in these two previous studies, and these participants with high educational level represented only $47 \%$ of the study population. This low level of knowledge is however similar to that reported among health care workers in Northwest Ethiopia, where only $52 \%$ of the respondents were knowledgeable about hepatitis B infection [15].

Almost all participants (96\%) recognized that health care workers are more at risk of being infected with HBV than the general population, and over two-thirds of participants considered that the vaccine against $\mathrm{HBV}$ is safe. Similarly, among surgical residents and medical students in Cameroon, we found that respectively $78.4 \%$ of participants and $97.3 \%$ thought that the $\mathrm{HBV}$ vaccine was safe and $87.4 \%$, and $78.4 \%$ recognized that HCW were more at risk $[10,11]$. Our participants felt that vaccination should be mandatory for health care providers (93\%) and all (100\%) participants agreed to recommend HBV vaccination to their colleague. However, only $19 \%$ were vaccinated. 
Similar low uptake of $\mathrm{HBV}$ vaccine was reported in our previous studies among surgical residents (24.5\%) [10] and medical students (18\%) [11], and in another study among health care workers in Yaoundé (8.8\%) [12]. Among health profession trainees, HBV vaccine coverage was reported to be $47.7 \%$ among medical students [16] and $37.9 \%$ among dental students in Nigeria [17], $76.8 \%$ among medical students and $46.7 \%$ among interns in Palestine [18]. A study among theatre personnel in Nigeria reported a $\mathrm{HBV}$ uptake rate of $26.8 \%$ [19], while $5.4 \%$ and $52 \%$ of health care workers respectively in Northwest Ethiopia [15] and Libya [20] reported that they took three or more doses of $\mathrm{HBV}$ vaccine.

Studies have shown that awareness of risk among health care workers is an important factor affecting HBV vaccine uptake [21-23]. Contrariwise, the low vaccine coverage among our participants contrasts with the fact that almost all of them (96\%) considered that they are at a higher risk of HBV infection than the general population. The main reason of this low vaccine uptake was reported to be lack of sufficient information on the vaccine. This reason is in keeping with the fact that only $41 \%$ of participants had been informed by their training institution or by the administration of their health facility about the importance of being vaccinated against HBV. Therefore, raising the awareness of health care workers about the importance of being vaccinated against $\mathrm{HBV}$ and providing them with relevant information about $\mathrm{HBV}$ vaccine is paramount to scale up vaccine uptake in this population at high risk of $\mathrm{HBV}$ infection.

Another important reason of not being vaccinated was lack of money to pay for the vaccine. This stresses the need to subsidize HBV vaccination among health care workers. Considering the fact that HBV vaccine is freely provided to children inside the national Expanded Programme for immunization (EPI) since 2005, our health care system should afford subsidizing the vaccine for health care workers bearing in mind their high risk of being contaminated by or to contaminate their patients. Indeed, there is an urgent need for health policies advocating $\mathrm{HBV}$ vaccination among health care workers in Cameroon in order to curb the burden and occupational risk of $\mathrm{HBV}$ infection in the hospital environment.

Furthermore, we found that only 9 out of the 19 participants who were vaccinated had HBs Ab titers $\geq 100 \mathrm{IU} / \mathrm{l}$ indicating a good response to vaccination. In fact, only $9 \%$ of our study population was adequately vaccinated and thus protected against $\mathrm{HBV}$ infection. Among the 9 participants who said they took three doses of the vaccine, 2 had poor response to vaccination (HBs Ab titers < $100 \mathrm{IU} / \mathrm{l}$ ), highlighting the necessity to do an immune response test after the 3 doses of the minimum $\mathrm{HBV}$ vaccination course, in order to have a booster dose in case of poor immune response.

The prevalence of HBs Ag in our study population was $11 \%$, with $10 \%$ chronic carriers and $1 \%$ of active HBV infection. These health care workers may develop fatal complications such as cirrhosis and hepatocellular carcinoma. These workers can also potentially transmit HBV to their patients. In Cameroon, seroprevalence of $\mathrm{HBs} \mathrm{Ag}$ has been reported to be $10.1 \%$ in a general population of blood donors [3], 10.2 \% among pregnant women [4] and $23.7 \%$ among HIV-infected patients [5]. Among health care workers, a study in Yaoundé reported a prevalence of $6.6 \%$ lower than what we found [12]. Among health care workers the rate of HBs Ag positivity was $1.8 \%$ in a study in Libya [20], $2.9 \%$ in Rwanda [24], 7 \% in Tanzania [25] and $8.1 \%$ in Uganda [26]. The higher frequency of HBV infection in our study as compared to those from other countries is mainly due to the high prevalence of the infection in the general population.

Finally, $62 \%$ of our participants had never been exposed to $\mathrm{HBV}$ and therefore susceptible or at risk of HBV infection. These subjects highly need vaccination to be protected. The importance of vaccination is highlighted by the very poor preventive practices of participants after exposure to blood. Indeed, those exposed did not notify the exposure to the authorities in their health facilities, to seek post-exposure prophylaxis. Moreover, the majority (75 \%) initially only considered the risk of HIV infection and only $25 \%$ considered that of HBV infection. This could be due to the fact that, in most public health awareness campaigns, a lot of emphasis is made on HIV/AIDS, leading to greater consciousness on HIV in the general population and among health care workers as opposed to HBV despite its high infectivity. While it is important to improve attitudes towards post-exposure prophylaxis, vaccination against HBV remains overriding.

\section{Conclusion}

Health care workers in the Mvog-Ada Health Area are at high risk of $\mathrm{HBV}$ infection because of very low vaccine uptake and poor post-exposure practices. Their knowledge of HBV infection is non-optimal, with lack of information and support regarding HBV vaccination. The prevalence of HBs Ag is high (11\%). There is urgent need for health policies advocating HBV vaccination among health care workers in Cameroon in order to curb the burden and occupational risk of $\mathrm{HBV}$ infection in the hospital environment.

\section{Abbreviations}

anti-BHs Ab, hepatitis B surface antibodies; anti-HBc Ab, hepatitis B core antibodies; anti-HBe Ab, hepatitis B e antibodies; EDTA, Ethylene Di-amine Tetra-acetic Acid; $\mathrm{HBe}$ Ag, hepatitis B e antigen; HBs Ag, hepatitis B surface antigen; HBV, hepatitis B virus; LMIC, low- and middle-income countries 


\section{Acknowledgements}

We are grateful to all the Healthcare personnel who have willingly participated in this research.

\section{Funding}

This research did not receive any external funding.

\section{Availability of data and materials}

Data will be available from the corresponding author upon request.

\section{Authors' contributions}

Study conception and design: OHTP, JJNN, RSM. Data collection: OHTP. Data analysis and interpretation: JJNN, OHTP. Drafting: JJNN, OHTP, JRNN, LNA. Critical discussion and manuscript revision: JJNN, OHTP, JRNN, LNA, JJRB, VNZ, RMS. Funding: OHTP. Decision to submit the final draft: all authors. All authors read and approved the final manuscript.

\section{Competing interests}

The authors declare that they have no competing interests.

\section{Consent for publication}

Not applicable.

\section{Ethics approval and consent to participate}

This study was granted ethical approval by the Institutional Review Board of the Higher Institute of Health Professions, Faculty of Sciences, University of Ngaoundéré, Cameroon, and was performed in accordance with the guidelines of the Helsinki Declaration. All components of the study were explained to each participant, and a written informed consent was obtained from him/her before inclusion in the study. Participants found to be infected with HBV were referred for appropriate management.

\section{Author details}

${ }^{1}$ Mvog-Ada Health Center, Djoungolo Health District, Yaoundé, Cameroon. ${ }^{2}$ Higher Institute of Health Professions, Faculty of Sciences, University of Ngaoundéré, Ngaoundéré, Cameroon. ${ }^{3}$ Department of Medicine, Groote Schuur Hospital and University of Cape Town, 7295 Cape Town, South Africa. ${ }^{4}$ Medical Diagnostic Center, Yaoundé, Cameroon. ${ }^{5}$ Department of Public Health, Faculty of Medicine and Biomedical Sciences, University of Yaoundé 1, Yaoundé, Cameroon. ${ }^{6}$ Clinical Research Education, Networking and Consultancy (CRENC), Douala, Cameroon. ' 5 chool of Public Health, The University of Queensland, QLD 4006 Brisbane, Australia. ${ }^{8}$ Department of Epidemiology and Public Health, Pasteur Center of Cameroon, Yaoundé, Cameroon. ${ }^{9}$ Centre for Evidence-based Health Care, Faculty of Medicine and Health Sciences, Stellenbosch University, Cape Town, South Africa. ${ }^{10}$ Faculty of Medicine and Biomedical Sciences, University of Yaoundé 1, Yaoundé, Cameroon.

Received: 7 February 2016 Accepted: 28 July 2016

Published online: 03 August 2016

\section{References}

1. Schweitzer A, Horn J, Mikolajczyk RT, Krause G, Ott JJ. Estimations of worldwide prevalence of chronic hepatitis B virus infection: a systematic review of data published between 1965 and 2013. Lancet. 2015;386(10003):1546-55.

2. Lozano R, Naghavi M, Foreman K, Lim S, Shibuya K, Aboyans V, Abraham J, et al. Global and regional mortality from 235 causes of death for 20 age groups in 1990 and 2010: a systematic analysis for the Global Burden of Disease Study 2010. Lancet. 2012;380:2095-128.

3. Noubiap JJ, Joko WY, Nansseu JR, Tene UG, Siaka C. Sero-epidemiology of human immunodeficiency virus, hepatitis B and C viruses and syphilis infections among first-time blood donors in Edéa, Cameroon. Int J Infect Dis. 2013;17:e832-7.

4. Noubiap JJ, Nansseu JR, Ndoula ST, Bigna JJ, Jingi AM, Fokom-Dongue J. Prevalence, infectivity and correlates of hepatitis B virus infection among pregnant women in a rural district of the Far North Region of Cameroon. BMC Public Health. 2015;15(1):454.

5. Noubiap JJ, Aka P, Nanfack AJ, Agyingi LA, Ngai JN, Nyambi PN. Hepatitis B and C Co-Infections in Some HIV-Positive Populations in Cameroon, West Central Africa: Analysis of Samples Collected Over More Than a Decade. PLoS ONE. 2015;10(9), e0137375.
6. West DJ. The risk of hepatitis B infection among health professionals in 301 the United States: a review. Am J Med Sci. 1984;287(2):26-33.

7. U.S. Public Health Service. Updated U.S: public health service guidelines for the management of occupational exposures to HBV, HCV, and HIV and recommendations for postexposure prophylaxis. MMWR Recomm Rep. 2001;50:1-52.

8. ECRI. Needle stick-prevention devices. Health Devices. 1999 Oct; 28 (10): 381-408.

9. Prüss-Üstün A, Rapiti E, Hutin Y. Estimation of the global burden of disease attributable to contaminated sharps injuries among health-care workers. Am $J$ Ind Med. 2005;48(6):482-90.

10. Noubiap JJ, Nansseu JR, Kengne KK, Wonkam A, Wiysonge CS. Low hepatitis B vaccine uptake among surgical residents in Cameroon. Int Arch Med. 2013;7(1):11.

11. Noubiap JJ, Nansseu JR, Kengne KK, Tchokfe SN, Agyingi LA. Occupational Exposure to Blood, Hepatitis B Vaccine Knowledge and Uptake among Medical Students in Cameroon. BMC Med Educ. 2013;13(1):148.

12. Noah Noah D, Njouom R, Bonny A, Pirsou Meli J, Biwole Sida M. HBs antigene prevalence in blood donors and the risk of transfusion of hepatitis $B$ at the central hospital of Yaounde, Cameroon. Open J Gastroenterol. 2011;1:23--2.

13. Mast EE, Margolis HS, Fiore AE, Brink EW, Goldstein ST, Wang SA, Moyer LA, Bell BP, Alter MJ. Advisory Committee on Immunization Practices (ACIP). A comprehensive immunization strategy to eliminate transmission of hepatitis $B$ virus infection in the UnitedStates: recommendations of the Advisory Committee on Immunization Practices (ACIP) part 1: immunization ofinfants, children, and adolescents. MMWR Recomm Rep. 2005:54:1-31.

14. Mast EE, Weinbaum CM, Fiore AE, Alter MJ, Bell BP, Finelli L, Rodewald $L E$, Douglas JM Jr, Janssen RS, Ward JW; Advisory Committee on Immunization Practices (ACIP) Centers for Disease Control and Prevention (CDC). A comprehensive immunization strategy to eliminate transmission of hepatitis $B$ virus infection in the United States: recommendations of the Advisory Committee on Immunization Practices (ACIP) Part II: immunization of adults. MMWR Recomm Rep. 2006;55(RR-16):1-33.

15. Abeje $G$, Azage M. Hepatitis $B$ vaccine knowledge and vaccination status among health care workers of Bahir Dar City Administration, Northwest Ethiopia: a cross sectional study. BMC Infect Dis. 2015;15:30. doi:10.1186/s12879-015-0756-8.

16. Okeke EN, Ladep NG, Agaba El, Malu AO. Hepatitis B vaccination status and needle stick injuries among medical students in a Nigerian University. Niger J Med. 2008;17(3):330-2.

17. Sofola OO, Folayan MO, Denloye OO, Okeigbemen SA. Occupational exposure to bloodborne pathogens and management of exposure incidents in Nigerian dental schools. J Dent Educ. 2007;71(6):832-7.

18. Al-Dabbas M, Abu-Rmeileh NM. Needlestick injury among interns and medical students in the occupied palestine territory. East Mediterr Health J. 2012;18(7):700-6.

19. Kesieme EB, Uwakwe K, Irekpita E, Dongo A, Bwala KJ, Alegbeleye BJ. Knowledge of hepatitis $B$ vaccine among operating room personnel in Nigeria and their vaccination status. Hepat Res Treat. 2011;2011:157089.

20. Elzouki AN, Elgamay SM, Zorgani A, Elahmer O. Hepatitis B and C status among health care workers in the five main hospitals in eastern Libya. $J$ Infect Public Health. 2014;7(6):534-41.

21. Doebbeling BN, Ferguson KJ, Kohout FJ. Predictors of hepatitis B vaccine acceptance in health care workers. Med Care. 1996;34(1):58-72.

22. Taalat M, Kandell A, El-Shoubary W, Bodenschatz C, Khairy I, Oun S, Mahoney FJ. Occupational exposure to needle stick injuries and hepatitis B vaccination coverage among health care workers in Egypt. Am J Infect Control. 2003;31 (8):469-74.

23. Shim BM, Yoo HM, Lee AS, Park SK. Seroprevalence of hepatitis B virus among health care workers in Korea. J Korean Med Sci. 2006;21(1):58-62.

24. Kateera F, Walker TD, Mutesa L, Mutabazi V, Musabeyesu E, Mukabatsinda C, Bihizimana P. Kyamanywa P. Karenzi B, Orikiiriza JT. Hepatitis B and C seroprevalence among health care workers in a tertiary hospital in Rwanda. Trans R Soc Trop Med Hyg. 2015;109(3):203-8.

25. Mueller A, Stoetter L, Kalluvya S, Stich A, Majinge C, Weissbrich B, Kasang C. Prevalence of hepatitis $B$ virus infection among health care workers in a tertiary hospital in Tanzania. BMC Infect Dis. 2015;15:386.

26. Ziraba AK, Bwogi J, Namale A, Wainaina CW, Mayanja-Kizza H. Seroprevalence and risk factors for hepatitis B virus infection among health care workers in a tertiary hospital in Uganda. BMC Infect Dis. 2010;10:191. 